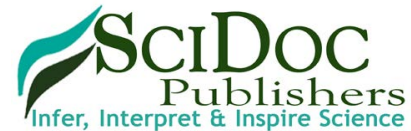

International Journal of Genomics, Proteomics, Metabolomics \& Bioinformatics (IJGPMB) ISSN: 2577-4336

\title{
Genetic Characterization and Gene Expression of Bile Salt Hydrolase (bsh) from Lactobacillus reuteri CRL 1098, a Probiotic Strain
}

Research Article

Bustos $\mathrm{AY}^{1^{*}}$, Font de Valdez $\mathrm{G}^{1,2}$, Raya $\mathrm{R}^{1}$, Taranto $\mathrm{MP}^{1}$

${ }^{1}$ Centro de Referencia para Lactobacilos (CERELA-CONICET) - Chacabuco 145 (T4000ILC) San Miguel de Tucumán, Argentina.

${ }^{2}$ Facultad de Bioquímica, Química y Farmacia, Universidad Nacional de Tucumán, Ayacucho 491 (T4000INI) San Miguel de Tucumán, Argentina.

\section{Abstract}

Intestinal microbes containing the bile salt hydrolase (BSH) enzyme, releases free $\mathrm{BA}$ plus aminoacids from conjugated BA. $\mathrm{BSH}$ activity trigger scholesterol consumption in liver to synthesize BA de novo leading to consequential cholesterol lowering. Lactobacillus (L.) reuteri CRL 1098 is a probiotic bacterium with a proven hypocholesterolemic effect associated to its ability to hydrolyze BA. In this work we characterized the bile salt hydrolase (bsh) operon of CRL 1098 strain as a single open reading frame of 978 nucleotides that encodes a predicted protein of 325 amino acids, with a calculated mass of $36098.1 \mathrm{Da}$ and a theoretical $\mathrm{pI}$ of 4.81. Moreover, deduced BSH protein had high similarity with BSHs of other L. reuteri strain and also exhibited similarity to the Pencillin V amidases of Listeria and Bacillus strains. Five catalytically important amino acids were highly conserved in Lactobacillus, Enterococcus and Bifidobacterium strains while four amino acid motifs around these active sites, were only partially conserved. After the bsh gene product was expressed in the heterologous host Lactococcus lactis NZ9000. The activity was specific towards bile acids but not against alternative substrates. Finally, a significant up-regulation of the bsh gene was observed at $\mathrm{pH} 5.2$ (optimal $\mathrm{pH}$ of $\mathrm{BSH}$ activity).

Our studies suggest that BSHs would have an important but so far unknown role in the physiology and lifestyle of L. reuteri strains. The present work would be useful to unravel the ecological role of the BSH and to deepen their influence in the reduction of blood cholesterol levels.

Keywords: Lactobacillus reuteri; Bile Salt Hydrolase; Molecular Cloning; Gene Expression.

\section{Introduction}

In vertebrates, Bile Acids (BA) play an essential role in lipid digestion, acting as a detergent that emulsifies and solubilizes dietary lipids and lipid-soluble vitamins. BA are synthesized from cholesterol, conjugated with taurine or glycine in the liver and secreted into the duodenum. Intestinal microbes, containing the Bile Salt Hydrolase (BSH) enzyme, release the free BA plus amino acids from conjugated BA.

BSHs and also penicillin $\mathrm{V}$ amidases (PVA) (EC 3.5.1.11) belong to the choloylglycine hydrolase family of enzymes and have been classified as N-terminal nucleophilic hydrolases with an $\mathrm{N}$-terminal cysteine residue [1]. BSH activity has been described among a wide variety of genus, including Lactobacillus
[2-7], Bifidobacterium [8-10], Clostridium (C). [11], Listeria [12], and Enterococcus [13]. Additionally, a number of bsh genes from Lactobacillus plantarum [14,6], Lactobacillus johnsonii [2], Lactobacillus fermentum [3], Lactobacillus casei [15] and Bifidobacterium [16-18] strains have been cloned and characterized. Interestingly, the presence and genetic organization of $b s h$ genes are highly variable and also, several strains possess more than one BSH homologo, which in most cases are not identical [19].

Probiotics with $\mathrm{BSH}$ activity have received much attention on account of its influence on serum cholesterol lowering. BA deconjugation enhances its excretion through the feces and could lead to serum cholesterol reduction by increasing its demand for de novo synthesis of BA [5, 20, 21]. Therefore, the World Health Organization (WHO) recommended BSH activity as one of the

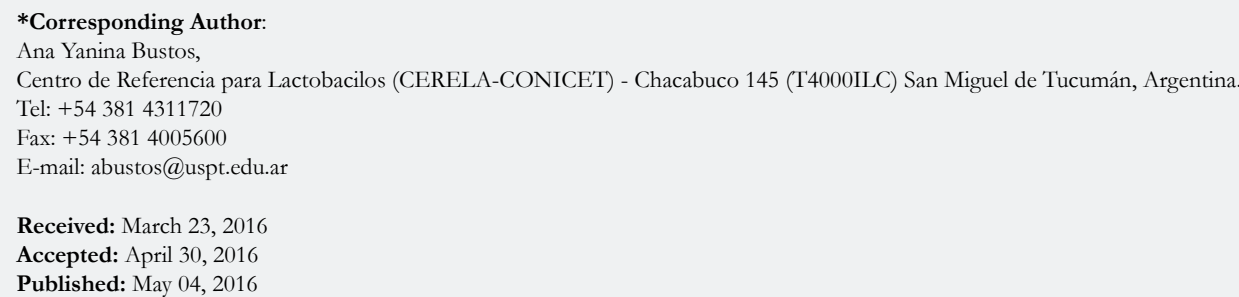

Citation: Bustos AY, Font de Valdez, Raya R, Taranto MP (2016) Genetic characterization and gene expression of bile salt hydrolase (bsh) from Lactobacillus reuteri CRL 1098, a probiotic strain. Int J Genomics Proteomics Metabolomics Bioinformatics. 1(1), 1-8. doi: http://dx.doi.org/10.19070/2577-4336-160001

Copyright: Bustos $\mathbf{A Y} \mathbf{Y}^{\circ}$ 2016. This is an open-access article distributed under the terms of the Creative Commons Attribution License, which permits unrestricted use, distribution and reproduction in any medium, provided the original author and source are credited. 
main criteria to propose a microorganism as probiotic along with their ability to resist the harsh gut environment and to colonize gastrointestinal epithelia [22].

L. reuteri CRL 1098 is a probiotic bacterium with a proven hypocholesterolemic effect closely associated to its ability to hydrolyze BA [20, 23, 24]. Moreover, this strain displays a moderate immune stimulant effect [25] and ability to produce corrinoids with cobalamin activity $[26,27]$. BSH enzymes from $L$. reuteri strains are and their relation to cholesterol reduction have been previously documented [24, 28]; however, data on its bsh gene are still poor. Therefore, the aim of this study was to identify, clone and characterize the bsh gene of L. reuteri CRL 1098, and to investigate the functionality of the $b s h$ gene product against BA and alternative substrates. Finally, the regulation of $b s h$ at different $\mathrm{pH}$ was examined by Real Time-PCR.

\section{Materials and Methods}

\section{Bacterial strains and growth conditions}

L. reuteri strain CRL 1098 was grown at $37^{\circ} \mathrm{C}$ in MRS broth [29]. The heterologous-expression host Lactococcus (Lac.) lactis NZ9000 was grown at $30^{\circ} \mathrm{C}$ in M17 broth (Biokar Diagnostics, Beauvais Cedex - France) supplemented with $0.5 \%$ glucose (w/v) [M17Glu $0.5 \%$, without aeration. Escherichia (E.) coli $\mathrm{DH} 10 \beta$ was grown at $37^{\circ} \mathrm{C}$ on Luria Bertani (LB) medium in aerobic conditions. When necessary, $1 \mathrm{mM}$ or $10 \mathrm{mM}$ of conjugated BA (Sigma Aldrich, St. Louis, MO, USA), antibiotics and others reagents were added to the media. For Lac.lactis strain development, $5 \mu \mathrm{g} /$ $\mathrm{ml}$ erythromycin (Erm) was used; $100 \mu \mathrm{g} / \mathrm{ml}$ ampicillin, $40 \mathrm{mg} /$ $\mathrm{ml} \mathrm{X}$-gaL, $100 \mathrm{mM}$ isopropil- $\beta$-D-1-tiogalactopiranósido (IPTG), $15 \mu \mathrm{g} / \mathrm{ml}$ chloramphenicol (Cmp) or $10 \mu \mathrm{g} / \mathrm{ml}$ tetracycline (Tet) were used to development of E. coli DH10 3 .

\section{DNA manipulations}

Genomic DNA was extracted from $L$. reuteri strain following the procedure previously described [30]. Plasmid DNA was isolated from E. coli on a small scale, using the alkaline lysis method [31]. Plasmid DNA isolation and electroporation technique used for Lac. lactis NZ9000 were performed as described by Lambert et al. [6]. Purification of DNA fragments from agarose gels was performed using the PCR AccuPrep ${ }^{\circledR}$ Purification Kit (Bionner, Korea). Restriction endonucleases, Taq DNA polymerase, T4 DNA ligase and Klenow enzyme were used as indicated by the manufacturers (Promega and Invitrogen, Buenos Aires, Argentina). Primers were synthetized from Invitrogen.

\section{Cloning bsh gene}

PCR primers from bsh gene of L. reuteri DSM20016 (WP_003668136.1) were designed using Primer3 Software to determine the bsh gene sequence of CRL 1098 strain. PCR amplification reactions was conducted in a Thermal Cycler System MyCycler $^{\mathrm{TM}}$ using genomic DNA of CRL 1098 strain as template and following a protocol previously described [32] except that the annealing step was performed at $55^{\circ} \mathrm{C}$ for $1 \mathrm{~min}$.

The PCR product was cloned in $\mathrm{TOPO}^{\circledR}$-TA Cloning (Invitrogen, Breda, The Netherlands). The recombinant plasmid, named
pBTR1 was propagated into calcium chloride competent cells of the intermediate cloning hosts E. coli DH10 $\beta$ using the heat shock method [33]. Recombinant cells were recovered in LB medium with ampicillin and were determined using universal primers T3 (5'GCAATTAACCCTCACTAAAGG3') and T7 (5'TAATACGACTCACTATAGGG3') at the Servicio de Diagnóstico Genético de Animales Domésticos (GAD), Facultad de CienciasVeterinarias, Universidad Nacional de La Plata.

\section{Sequence analysis}

The nucleotide and the predicted amino acid sequences of BSH of $L$. reuteri CRL 1098 were analyzed and compared with reference sequences available in GenBank (EMBL) by BLAST program at the website of the NCBI (http://www.ncbi.nlm.nih.gov). Promoter sequences were predicted by using a Neural Network Promoter Prediction program (NNPP), versión 2.2 (http:// www.fruitfly.org/seq_tools/promoter.html), while the secondary structure of the putative transcription termination sequence was predicted using http://transterm.cbcb.umd.edu. Multiple amino acid sequence alignments and phylogenetic tree were carried out using ClustalW software package. The nucleotide sequence of the $b s h$ gene from L. reuteri CRL 1098 was submitted to the GenBank database under accession number FJ006722.1.

\section{Heterologous expression of $b s h$ gene}

The bsh gene of L. reuteri CRL 1098 was expressed in the GRAS organism (Generally Recognized as Safe) Lac. lactis NZ9000. The $b s h$ gene was recovered from the pBTR1 as a 1.2-kb BamHI-EcoRV fragment and cloned into the Bam HI-SalI sites of plasmid pSA3 (inactivating the tet gene). The recombinant plasmid pBTR3 was purified from Cmp-resistant, Tet-sensitive E. coli cells and used to transform Lac. lactis NZ9000. Electrocompetent cells prepared as previously described [6] were exposed to a single electrical pulse delivered by a Gene-Pulser (Bio-Rad Laboratories, Richmond, California) set at $25 \mu \mathrm{F}$ and normally at $2.0 \mathrm{kV}$. Recombinant cells of Lac. lactis NZ9000 (pBTR3) were recovered in M17-Glu 0.5\% broth with Erm.

\section{BSH activity and alternative acylase functionality}

Stationary phase cells $\left(\mathrm{DO}_{600 \mathrm{~nm}}: 2\right)$ of Lac. lactis NZ9000-pBTR3 were harvested by centrifugation $(8.600 \mathrm{x} \mathrm{g}, 10 \mathrm{~min})$ at room temperature and cell pellets were washed twice with equal volume of saline solution $(\mathrm{NaCl} 0.85 \% \mathrm{wt} / \mathrm{vol})$. Then, cells were concentrated 5-fold in $100 \mathrm{mM}$ sodium acetate buffer ( $\mathrm{pH}$ 5.2) containing $1 \mathrm{mM}$ dithiothreitol (DT') and $1 \mathrm{~g}$ of zirconium beads and mechanically disrupted in a Mini-Beadbeater-8TM Cell Disrupter using 7 treatments of $1 \mathrm{~min}$ interspaced by $1 \mathrm{~min}$ in ice. Following centrifugation, cells-free extracts (CFE) were obtained and kept at $-20^{\circ} \mathrm{C}$ until use. The reaction mixture $(1 \mathrm{ml})$ contained $10 \mathrm{mM}$ of conjugated BA glycodeoxycolic acid (GDCA), glycocolic acid (GCA), taurodeoxycholic acid (TDCA) and, taurocholic acid (TCA), penicillin V, ampicillin, ketocaproyl-homoserine lactone, or oxooctanoyl-homoserine lactone (Sigma, Zwijndrecht, The Netherlands), $100 \mathrm{mM}$ sodium acetate buffer ( $\mathrm{pH}$ 5.2), $1 \mathrm{mM}$ DTT and $100 \mu \mathrm{l}$ of CFE. The reaction was incubated $6 \mathrm{~h}$ at $37^{\circ} \mathrm{C}$, after which the hydrolase activity was inactivated by the addition of $500 \mu \mathrm{l}$ of $20 \% \mathrm{wt} / \mathrm{vol}$ trichloroacetic acid. Amino 
acids liberated were measured with the o-phthalaldehyde (OPA) method [34] and results were expressed as mmol of amino acid released $/ \mu \mathrm{g}$ protein. CFE of L. reuteri CRL 1098 and Lac. lactis NZ9000-pSA3 cells, obtained as described above, were used as positive and negative controls, respectively.

\section{RNA isolation}

RNA isolation from L. reuteri CRL 1098 was performed as previously described with some modifications [35]. An overnight culture of CRL 1098 strain was inoculated in fresh MRS broth $(1 \% \mathrm{v} / \mathrm{v})$ with $1 \mathrm{mM}$ of GDCA at a fixed $\mathrm{pH}(4.5,5.2$ and 6.5$)$. The cells were incubated until mid-exponential phase (OD560 $\mathrm{nm} 0.9)$ and harvested by centrifugation at $3500 \mathrm{x}$ for $10 \mathrm{~min}$ followed by cell pellet suspension in ice-cold TE buffer (10 $\mathrm{mM}$ Tris- $\mathrm{HCl}, 1 \mathrm{mM}$ EDTA, $\mathrm{pH}$ 7.5). The cell suspension was transferred to a 2-ml screw-cap microcentrifuge tube containing $0.8 \mathrm{~g}$ of zirconium beads, $0.18 \mathrm{~g}$ of macaloid, $50 \mu \mathrm{l}$ of $10 \%$ (wt/ vol) SDS, and $500 \mu \mathrm{l}$ of water-saturated phenol-chloroform (1:1). Cells were mechanically disrupted in a Mini-Beadbeater-8TM Cell Disrupter using 7 treatments of 1 min interspaced by 1 min ion ice. Subsequently, the RNA was purified from the upper aqueous phase of the cell extract by phenol-chloroform extraction, precipitated with absolute ethanol, washed with $70 \%$ ethanol and resuspended in MilliQ water. The RNA obtained was stored in aliquots at $-70{ }^{\circ} \mathrm{C}$ until further use.

\section{Real-time PCR assays}

RNA samples were treated with the RNase-free DNase I set (Tecnolab, Buenos Aires, Argentina) according to the manufacturer's recommendations. The absence of DNA in the samples was confirmed by PCR. For reverse transcriptase PCR (RT-PCR) analysis, cDNA was synthesized from RNA by using SuperScript II reverse transcriptase (Invitrogen, Breda, The Netherlands) following the manufacturer's protocol. The resulting cDNA samples were used for Real-Time PCR amplification. Specific primers for bsh gene (RT-BSHF: 5'GGTTGGGATGGCAGGCCT'TAATT'T3' and RT-BSHR: 5'AACTTCT'TCGCT'TCAGCAACCGAG3') and housekeeping genes primers were designed to have melting temperatures of 60 to $65^{\circ} \mathrm{C}$ and amplicon sizes around $130 \mathrm{bp}$. RecA primers were used as internal gene control to normalize the amount of RNA added and the relative expression was calculated using the $2^{-\Delta \Delta C T}$ method [36] where $\Delta \Delta \mathrm{CT}=\left(\mathrm{CT}^{b s b}-\mathrm{CT}^{\mathrm{rec} A}\right)_{\mathrm{BA}^{-}}\left(\mathrm{CT}^{b s h}-\mathrm{CT}^{\mathrm{rec} A}\right)_{\mathrm{Control}}{ }^{\circ}$ Cells growing in MRS broth at $\mathrm{pH} 6.5$ were used as reference condition. The experiments were performed in an IQ iCycler (Biorad, Hercules, CA, USA) using the double stranded DNA intercalating fluorescent agent SYBR green for product detection. Each well contained SYBR green Master Mix, $0.05 \mu \mathrm{M}$ of each primer, and $30 \mathrm{ng} / \mu \mathrm{l}$ of template. Control PCRs were included to detect background contamination (no-template control) and remaining chromosomal DNA (RT reactions in which Superscript II was omitted). PCR specificity and product detection were checked post-amplification by examining the dissociation curves (melting curve) of the PCR products.

\section{Data analysis}

Data analysis was carried out using the software InfoStat 2014, FCA, Universidad Nacional de Córdoba, Argentina. URL http:/ / www.infostat.com ar. Analysis of variance (ANOVA) followed by
Tukey's multiple range tests were used to study any significant difference between means with a significance level of $P<0.05$. All data were presented as mean \pm standard deviation.

\section{Results and Discussion}

\section{Amplification and nucleotide sequence analysis of the $L$. reuteri CRL 1098 bsh gene}

The bsh gene of $L$. reuteri CRL 1098 was amplified using PCR primers (F1-BSH: 5'GCCCAAAGT'TCAAGGACAAGCAGA3' and R2-BSH: 5'CCACGCAATCGCAACTGAAGTAT3') designed based on the $b s h$ gene encoding sequences of DSM 20016 strain (WP_003668136.1). The sequenced fragment contains a single open reading frame of 978 nucleotides (Supplemental material) bounded by a methionine start codon ATG and a TAA translation termination codon. A potential promoter-type structure is located from 22 to 72 nucleotides upstream of the ATG codon as well as a palindromic DNA sequence capable of forming a stem-loop structure downstream of the structural gene. In fact, a putative rho-independent type transcription terminator sequence $(\mathrm{AG}=-14.1 \mathrm{kcal} / \mathrm{mol}$ ) followed by a $\mathrm{T}$ rich region was recognized 20 nucleotides downstream of the stop codon (Supplemental material), indicating that the bsh gene of CRL 1098 strain is transcribed as a monocistronic unit. While polycistronic $b s h$ transcripts have been reported from $L$. johnsonii [37] and B. longum [18], monocistronic bsh transcripts are more common features in many other bacterial groups [1]. The encoded polypeptide ( 325 amino acids) has a calculated mass of 36098.1 Da, with a predicted pI of 4.81. The deduced amino acid sequence of the $\mathrm{N}$ terminal of the protein does not resemble a signal sequence typical for secretory proteins, suggesting an intracellular location of the BSH enzyme. BLAST analysis of the predicted amino acid sequence revealed that BSH of CRL 1098 is identical to L. reuteri DSM 20016 (WP_003668136.1) and share highest sequence identity (between 97 and 98\%) with the BSHs of L. reuteri TD1 (WP_019254138.1), L. reuteri 100-23 (WP_003665850), and L. reuteri ATCC 53608 (WP_003674287) and identities over $55 \%$ were also found with the BSH enzymes of several Lactobacillus and Enterococcus strains.

On the other hand, a conserved domain belonging to the superfamiliy of penicillin V acylase (PVA) (Accession: cd00542) was detected in BSH from CRL 1098 strain. PVA is an enzyme that catalyzes the hydrolysis of penicillin $\mathrm{V}$ to yield 6-APA and has an N-terminal nucleophilic cysteine, as do other members of the Ntn hydrolase family to which PVA belongs.

Multiple sequence alignment of the deduced amino acid sequences between BSH of CRL 1098 strain and other BSH and PVAs from Bacillus and Listeria strains was performed. As shown in Figure. 1 five catalytically important amino acids residues $(C, D, N, N$, and R) are highly conserved in CRL 1098 strain while four amino acid motifs (YFGRNXD, NEXGLXXAGLNF, VXVLTNNPXF, and SXSRFVRXAF), located around the active site were partially conserved. The Cys- 2 becomes a catalytic centre after removal of the initiation formyl methionine by an autoproteolytic process, which is one of the common features of the Ntn hydrolase superfamily [19]. The thiol (SH) group of Cys-2 has been shown to be essential for BSH catalysis [1,38]. However, the active sites showed little different between BSH and PVAs examined. For 
Figure 1. CLUSTAL alignment of BSHs

\author{
AAR39435.1 \\ WP_032743741.1 \\ ACH81023.1 \\ WP_004897162.1 \\ UNK_211317 \\ UNK_211315 \\ UNK_211316 \\ AAA22654.1 \\ CAC98525.1 \\ Consensus
}

AAR39435.1

WP_032743741.1

ACH81023.1

WP_004897162.1

UNK_211317

UNK_211315

UNK_211316

AAA22654.1

CAC98525.1

Consensus

AAR39435.1

WP_032743741.1

ACH81023.1

WP_004897162.1

UNK_211317

UNK_211315

UNK_211316

AAA22654.1

CAC98525.1

Consensus

AAR39435.1 WP_032743741.1 ACH81023.1 WP_004897162.1

UNK_211317

UNK_211315

UNK_211316

AAA22654.1

CAC98525.1

$\begin{array}{rrrrrr}10 & 20 & 30 & 40 & 50 & 60 \\ \text { | } & \mid & \mid & \mid & \mid\end{array}$

--MCTGVRFSDDEGNMYFGRNLDWSFSYGETILVTPRGYQYDYEYGAEGKSE-PNAVIGV --MCTGVRFSDDEGNTYFGRNLDWSFSYGETILVTPRGYHYDTVFGASGKAK-PNAVIGV --MCTSVIYTAG--DYYFGRNLDLEVNLGQEVVITPRNKTLEFREMPNLEH--HYAIIGM --MCTSIVYSSNN-HHYFGRNLDLEISFGEHPVITPRNYEFQYRKLPNKKA--KYAMVGM --MCTSIIFSPK--DHYFGRNLDLEITFGQQVVITPRNYTFKFRKMPSLKK--HYAMIGI --MCTSITYVTS--DHYFGRNFDYEISYNEVVTVTPRNYKLNFRKVNDLDT--HYAMIGI --MCTSITYTTN--DHYFGRNLDLEVSYNEQVTITPRNYPFVYRKVPKQES--HYAIIGM MLGCSSLSIRTTDDKSLFARTMDFTMEPDSKVIIVPRNYGIRLLEKENVVINNSYAFVGM --MCTSFVLETLDGKHLLSRTMDFAFILEANPTISPRNYGWKSSTDGANYIN-RYAFVGA

$$
\begin{array}{ccc}
*: . & : *^{*} .: * \quad \cdot \quad * * . & * . . \\
\text { MLMCTSI4YST22GDHYFGRNLDLE2SYGE2V2ITPRNY2F22RK3PNLK3NNHYAMIGM }
\end{array}
$$

$\begin{array}{cccccc}70 & 80 & 90 & 100 & 110 & 120 \\ \text { | } & \mid & \mid & \mid & \mid & \mid\end{array}$

GVVMTDRPMYFDCANEHGLAIAGLNFPGYASFAHEPVEGTENVATFEFPLWVARNFDSVD GVVMADRPMYFDCANEHGLAIAGLNFPGYASFVHEPVEGTENVATFEFPLWVARNFDSVD SIVRDDYPLYFDGVNEKGVGMAGLNFDGPAHYFPV-QEGKDNIASFELVPYILAAASSVA AIVEDNYPLYFDASNEEGLGIAGLNFDGPCHYFPE-VSGKNNVTPFELIPYLLSQYTTVA SLDMDDYPLYFDATNEKGLGMAGLNYPGNATYYEE-KENKDNIASFEFIPWILGQCSTIS AAGIADYPLYYDATNEKGLSMAGLNFSGYADYKEI-QEGKDNVSPFEFIPWILGQCSTVG AAVVDNYPLYYDATNEKGLSMAGLNFPGNAHFFDE-DPEKTNITPFEFIPWILSQCKNVE GSTDITSPVLYDGVNEKGLMGAMLYYATFATYADEPKKGTTGINPVYVISQVLGNCVTVD G-RELDKYIFADGLNEEGLSCASLYLPGEAVYAPAPVEGKINLAPQEFLLWLLGTCATIK

G3VMDDYPLYFDATNEKGL2MAGLNFPGYAHY2PEPVEGKDN2APFEFIPWILGQCSTVD

$\begin{array}{cccccc}130 & 140 & 150 & 160 & 170 & 180 \\ \mid & \mid & \mid & \mid & \mid & \mid\end{array}$

EVEEALKNVTLVSQVVPGQ-QESLLHWFIGDGT-RSIVVEQMADGMHVHHDDVDVLTNQP EVEEALRNVTLVSQIVPGQ-QESLLHWFIGDGK-RSIVVEQMADGMHVHHDDVDVLTNQP EAKKLLSNANIANINFSDKLQAAPLHWIIADKTGASVTVESTAKGLNVYDNPVGVLTNNP EVKEALKSVNLVKINFSEKLQLSPLHWLMADKTGESIVVESTLSGLHVYDNPVHVLTNNP EVKDLLSRINIADLNFSEKMQASSLHWLIADKTGTSLVVETDKDGMHIYDNPVGCLTNNP EAKKLLKNINLANINYSDELPLSPLHWLLADKE-KSIVIESMKDGLHIYDNPVGVLTNNP EARTLLADINLVNINFSEELPLSPLHWILADQE-TSIVIESVAEGLKIYDNPIGVLTNNP DVIEKLTSYTLLNEANIILGFAPPLHYTFTDASGESIVIEPDKTGITIHRKTIGVMTNSP DVEAKLSVINLVDQPVPLLGITTPLHWIFTDKSGRCVVIEPTETSLRIKENPVGVMTNTP

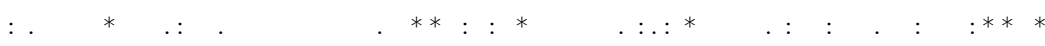
EVKELL2NINLVNINFSEKLQ2SPLHW2IADKTGRSIVVES2ADGLHIYDNPVGVLTNNP

$\begin{array}{cccccc}190 & 200 & 210 & 220 & 230 & 240 \\ \mid & \mid & \mid & \mid & \mid & \mid\end{array}$

TFDFHMENLRNYMCVSNEMAEPTTWGKAELSAWGAGVSMHGIPGDVSSPSRFVRVAYTNT TFDFHMENLRNYMCVSNEMAEPTSWGKASLTAWGAGVGMHGIPGDVSSPSRFVRVAYTNA EFPRQLLNLSNYRSIAPANPANVFAPNVDLPVYSRGLGTHFLPGGMDSESRFVKATFTKM EFPGQLSNLANYSNIAPSQPKNTLVPGVDLNLYSRGLGTHFLPGGMDSASRFVKVAFVRA QFPKQLFNLNNYADVSPKMPKNNFSDKVNMAGYSRGLGSHNLPGGMDSESRFVRVAFNKF SFDYQLFNLNNYRVLSSENPKNNFSNQISLNAYSRGMGGIGLPGDLSSVSRFVKATFTKL TFDYQLFNLNNYRSVSPTTPKNHFSDELDLSVYSRGMGGLGLPGDLSSASRFVKVAFTKL GYEWHQTNLRAYIGVTPNPPQDIMMGDLDLTPFGQGAGGLGLPGDFTPSARFLRVAYWKK RIEWHIENLRNYTGLQATQLAPVKFGEYMAKPFSQGTGTSKLPGGYTPPERFVRAAYLKE 


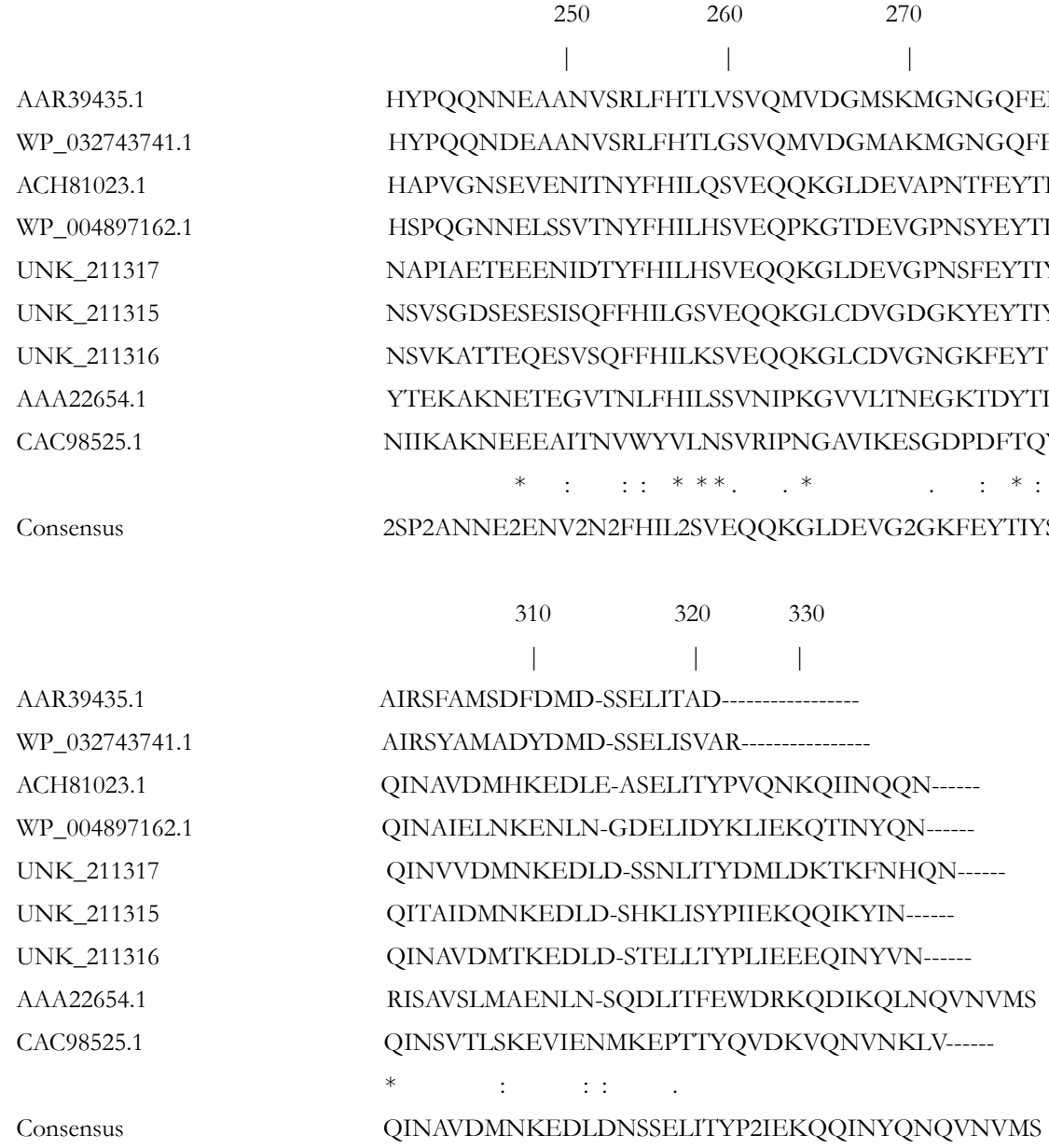

Protein sequences were obtained from the National Center for Biotechnology Information site (http://www.ncbi.nlm.nih.gov/). Alignments were performed by using CLUSTAL OMEGA (http://www.ebi.ac.uk/Tools/msa/clustalo/). Five proposed active sites (C, D, N, N, R) and four amino acid motifs, (YFGRNXD, NEXGLXXXGLNF, VXVLTNNPXF, and SXSRFVRXAF) are indicated by dark grey and grey shadow boxes, respectively. Identical amino-acids are marked by an asterisk, conserved substitutions are marked by two dots, and semi-conserved substitutions are marked by a single dot. AAR39435.1: $B i$ fidobacterium (Bif.) bifidum, WP_032743741.1: Bif. longum, WP_002313629.1: Enterococcus (Ent.) faecium, WP_019723927.1: Ent.mundtii, WP_004897162.1: Lactobacillus (L.) johnsonii, ACH81023.1: L. reuteri CRL 1098, WP_003546965.1: L. acidophilus. AAA22654.1: Bacillus sphaericus, CAC98525.1: Listeria monocytogenes.

example, the catalytic residue of Asn82 was replaced by Tyr82 in PVAs from Bacillus and Listeria strains. In addition, phylogenetic tree analysis (Figure 2) revealed that the bsh genes in L. reuteri strains were highly conserved but differed from the BSH enzymes from other genera and PVA from of Bacillus and Listeria strains.

Although the physiological role of the BSH has not yet been clearly established, the high level of conservation supports an important role of this gene in the physiology and lifestyle of $L$. reuteri strains.

\section{BSH expression in a heterologous host}

\section{Substrate specificity of $\mathrm{BSH}$}

The substrate specificity of the BSH of L. reuteri CRL 1098 was determined in enzyme assays with the four major human bile salts [19]. As shown in Figure 3 A, the enzymes exhibited a preference for glycine-conjugated BA over taurine-conjugated forms. Both
CRL 1098 strain as the recombinant Lac. lactis NZ9000 cells, expressing the $b s h$ gene showed activity against all BA tested, being the enzyme in both cases more active on GDCA. The highest affinity observed by the glycoconjugated substrates is consistent with our previous results $[39,38]$, as well as for numerous choloylglycine hydrolase enzymes described in the literature [19], which could be related to the higher toxicity of glycine-conjugated $\mathrm{BA}$ respect to taurine-conjugated $\mathrm{BA}[6]$. Although the precise mechanism is unknown, the capability to hydrolyze BA may contribute to the survival and persistence of bacterial strains in the intestinal tract, as was previously suggested by many authors $[19,39,1]$. Since deconjugated BAs display reduced solubility compared to their conjugated counterparts, especially at lower $\mathrm{pH}$ values, BA hydrolysis may lead to precipitation of the BA and thus may reduce the damage caused by these compounds. In this sense, a recent study reported that expression of $\mathrm{BSH}$ improved $\mathrm{BA}$ tolerance of Lac. lactis, however excessive production of BA micelles by BSH activity inhibited cell growth [40]. 
Figure 2. Phylogenetic tree illustrated the relationship among BSHs from Lactobacillus and PVA from Bacillus sphaericus and Listeria monocitogenes.

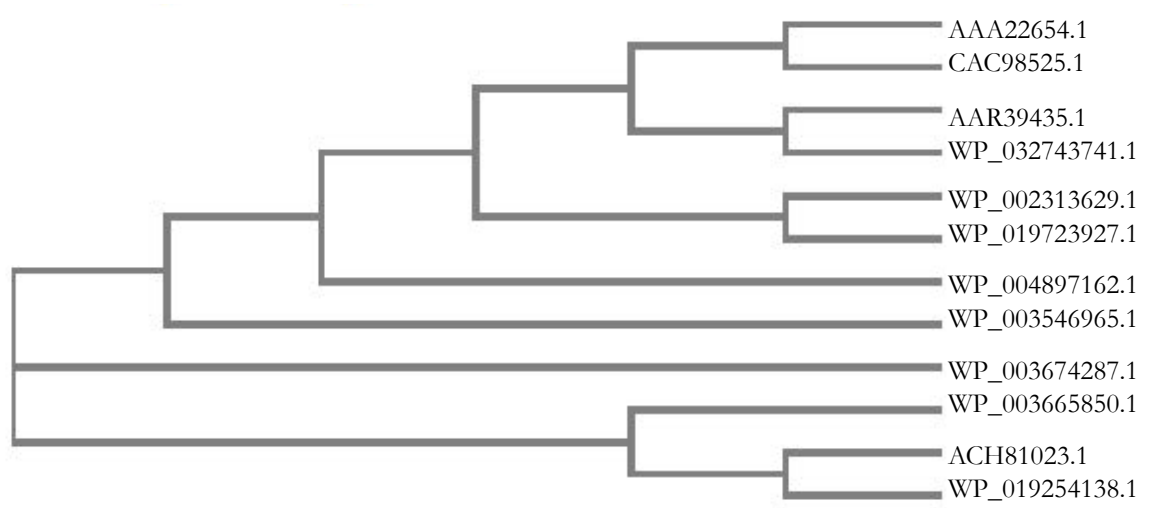

AAA22654.1: Bacillus sphaericus, CAC98525.1: Listeria monocytogenes, AAR39435.1: Bifidobacterium (Bif.) bifidum, WP_032743741.1: Bif. longum, WP 002313629.1: Enterococcus (Ent.) faecium, WP 019723927.1: Ent.mundtii, WP 004897162.1: Lactobacillus (L.) johnsonii, WP 003546965.1: L. acidophilus, WP_003674287.1: L. reuteri ATCC 53608, WP_003665850.1: L. reuteri100-23, ACH81023.1:L. reuteri CRL 1098, WP_019254138.1: L. reuteri TD1.

Figure 3. BSH activity and alternative acylase functionality of CFE of L. reuteri CRL 1098, Lac. lactis NZ 9000-pBTR3 and Lac. lactis NZ 9000-pSA3 against conjugated BA and alternative substrates.

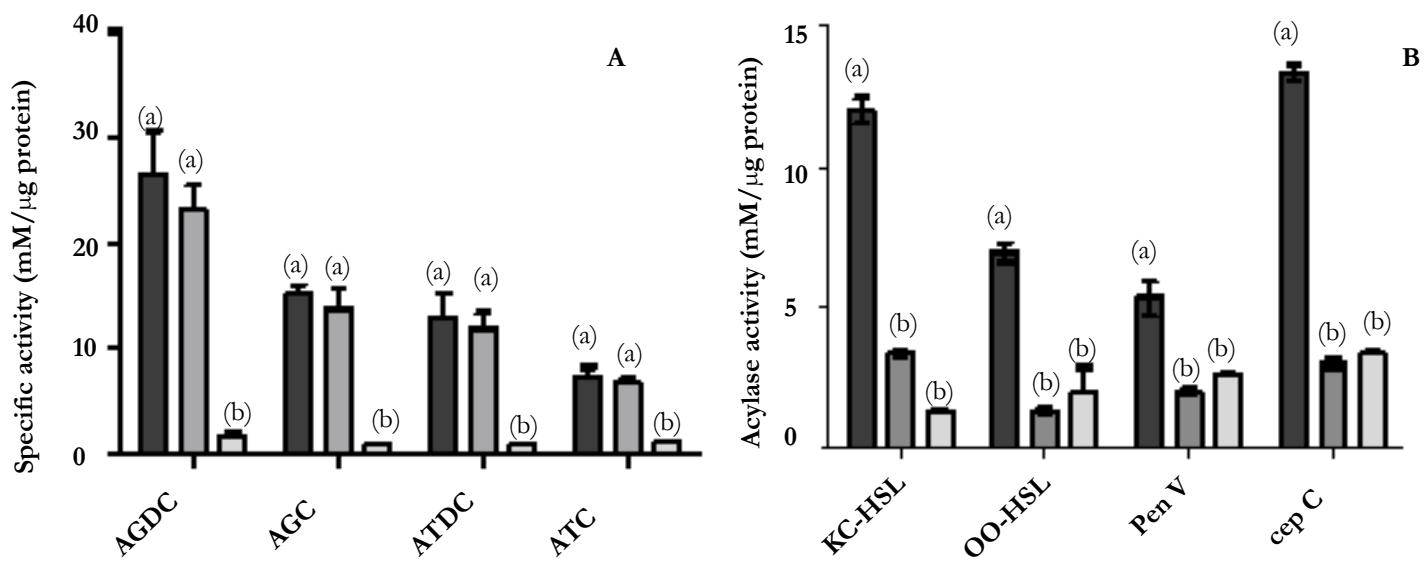

Hydrolase activity were measured in CFE by determining the amount of amino acids liberated by the BSH enzyme from conjugated BA (GDCA, GCA, TDCA and, TCA) and penicillin V (penV), ketocaproyl-homoserine lactone (KC-HSL), oxooctanoyl-homoserine lactone (OO-HSL), cephalosporin C (cep C). Variables with the same superscript letter show no significant differences between them $(P<0.05)$.

Figure 4. Relative expression of bsh gene in L. reuteri CRL 1098 cells grown in MRS broth at different pHs in the presence of GDCA.

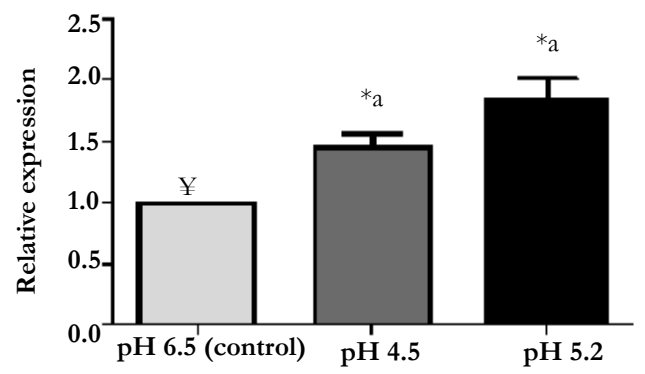

$\operatorname{RecA}$ primers were used as internal gene control to normalize the amount of RNA added and the relative expression was calculated using the $2^{-\Delta \Delta C T}$ method. $¥$ Cells growing in MRS broth at $\mathrm{pH} 6.5$ were using as reference condition and an arbitrary value of 1 was assigned. ${ }^{*}$ Indicate significant difference with the control; and the variables with the same letter show no significant differences between them $(P<0.05)$. 


\section{Alternative acilase activity}

The BSH protein of CRL 1098 shares some sequence homology (30.83\% of identity at amino acid level) with the experimentally verified PVA of List. monocytogenes EGDe (Figure 1), which are in turn related to $\beta$-lactam acylases and to acyl-homoserine lactone acylases, which play a key role in quorum sensing-dependent gene regulation in Gram-negative bacteria [1]. However, despite some BSHs share significant sequence homology with some of these enzymes and the type of bond target is identical; the structures of the respective substrates differ considerably. Thus, the hydrolysis ability of CRL 1098 strain and the heterologous host (Lac. lactis NZ9000-pBTR3) was evaluated on different substrates: penicillin $\mathrm{V}$, ampicillin, ketocaproyl-homoserine lactone and oxooctanoylhomoserine lactone. As shown in (Figure3) B, L.renteri CRL 1098 showed activity against all the substrates assayed, especially on ketocaproyl-homoserin lactone. However, the hydrolysis observed could not be related to the presence of $b s h$ gene since the heterologous strain (Lac. lactis NZ9000-pBTR3) - showed detectable activity only toward the conjugated $\mathrm{BA}$, confirming the specificity of BSH enzyme codified by bsh gene cloned. Lambert et al. [6] reported some acylase activity by $\mathrm{BSH} 2, \mathrm{BSH} 3$ and $\mathrm{BSH} 4$ of L. plantarum WCFS1 toward two types of acyl-homoserine lactones, indicating that these enzymes has a broad substrate specificity. However, these enzymes displayed very low hydrolysis activity against BA. In contrast, the presence of BSH1 appeared to correlate exclusively with the capability to hydrolyze BA and not the others studied substrates.

\section{Regulation of $b s h$ gene}

In a previous study we reported an up-regulation of the $b s h$ gene when exponential phase cells of $L$. reuteri CRL 1098 were growing in the presence of GDCA [41]. The BSH of L. reuteri CRL 1098 is active in a range of $\mathrm{pH}$ from 4.5 to 5.5 , with an optimum at $\mathrm{pH} 5.2$ [38]. In this study, the regulation of bsh gene of $L$. reuteri CRL 1098 in the presence of GDCA and at different $\mathrm{pH}$ values was evaluated using quantitative Real Time-PCR. As shown in (Figure 4), an increase in $b s h$ gene expression levels of $1.34 \pm$ 0.12 and $1.85 \pm 0.18$ at $\mathrm{pH} 4.5$ and 5.2, respectively, compared to $\mathrm{pH} 6.5$ (control condition) was observed. Koskenniemi et al. [42] and Duary et al. [43] reported the strong up regulation of $b s h$ genes upon bile exposure. Moreover, Bron et al. [44], applying DNA microarrays, reported an over-expression in $b s h 1$ gene and a significant reduction in $b s h 3$ gene in L. plantarum WCFS1 when cells were grown in porcine bile. On the contrary, Lambert et al. [6] reported that the expression of the four bsh genes of $L$. plantarum WCFS1 was not induced as a consequence of the exposure to porcine bile. Thus, the $\mathrm{BSH}$ regulation at genomic, transcriptomic or proteomic level strongly fluctuates according to the studied microorganisms. However, until now, the influence of $\mathrm{pH}$ on the gene expression of $b s h$ has not been described.

In the present work, the identification, cloning and characterization of the bsh gene of $L$. reuteri CRL 1098 is reported. It was found that the $b s h$ gene is organized as a single operon and is present as a single copy in the L. reuteri CRL 1098 and others $L$. reuteri genomes. The $b s h$ gene with its putative promotor region was cloned and expressed in the heterologous host Lac. lactis NZ9000. Hydrolysis activity was specific towards BA, in particular GDCA, but not against alternative substrates, confirming the functionality and specificity of the cloned gene. Finally, a significant upregulation of the $b s h$ gene was observed at $\mathrm{pH}$ 5.2. Our studies suggest that BSHs would have an important but so far unknown role in the physiology and lifestyle of $L$. reuteri strains. The present work would be useful for future investigations in order to deepen the influence of the $\mathrm{BSH}$ in the reduction of blood cholesterol levels in humans and animals and unravel its ecological role.

\section{Acknowledgement}

This research has been supported by grants from CONICET (PIP2011-0100406) and SECyT (PICT2011-0175).

\section{References}

[1]. Patel AK, Singhania RR, Pandey A, Chincholkar SB (2010) Probiotic bile salt hydrolase: current developments and perspectives. Appl Biochem Biotechnol 162(1): 166-180.

[2]. Chae J, Valeriano V, Kim GB, Kang DK (2013) Molecular cloning, characterization and comparison of bile salt hydrolases from Lactobacillus johnsonii PF01. J Appl Microbiol 114(1): 121-133.

[3]. Jayashree S, et al. (2014) Identification and characterization of bile salt hydrolase genes from the genome of Lactobacillus fermentum MTCC 8711. Appl Biochem Biotechnol 174(2): 855-866.

[4]. Joyce SA, Shanahan F, Hill C,Gahan CG (2014) Bacterial bile salt hydrolase in host metabolism: potential for influencing astrointestinal microbe-host crosstalk. Gut microbes 5(5): 669-674.

[5]. Kumar R, Grover S,Batish VK (2012) Bile salt hydrolase (Bsh) activity screening of Lactobacilli: in vitro selection of indigenous Lactobacillus strains with potential bile salt hydrolysing and cholesterol-lowering ability.Probiotics Antimicrob Proteins 4(3): 162-172.

[6]. Lambert JM, Bongers RS, De Vos WM, Kleerebezem M (2008) Functional analysis of four bile salt hydrolase and penicillin acylase family members in Lactobacillus plantarum WCFS1. Appl Environ Microbiol 74(15): 47194726.

[7]. Ren J, et al. (2011) All 4 Bile salt hydrolase proteins are responsible for the hydrolysis activity in Lactobacillus plantarum ST-III. J Food Sci 76(9): 622-628.

[8]. Jones BV, et al. (2008) Functional and comparative metagenomic analysis of bile salt hydrolase activity in the human gut microbiome.P Natl Acad Sci USA 105(36): 13580-13585.

[9]. Kim GB, Brochet M, Lee BH (2005) Cloning and characterization of a bile salt hydrolase (bsh) from Bifidobacterium adolescentis. Biotech Lett 27(12): 817-822.

[10]. Kim GB, Yi SH, Lee BH (2004) Purification and characterization of three different types of bile salt hydrolases from Bifidobacterium strains. J Dairy Sci 87(2): 258-266.

[11]. Kishinaka M, Umeda A, Kuroki S (1994) High concentrations of conjugated bile acids inhibit bacterial growth of Clostridium perfringens and induce its extracellular cholyglycine hydrolase. Steroids 59(8): 485-489.

[12]. Begley M, Gahan CG, Hill C (2002) Bile stress response in Listeria monocytogenes LO28: adaptation, cross-protection, and identification of genetic loci involved in bile resistance. Appl Environ Microbiol 68(12): 6005-6012.

[13]. Knarreborg A, Engberg RM, Jensen SK, Jensen BB (2002) Quantitative determination of bile salt hydrolase activity in bacteria isolated from the small intestine of chickens. Appl Environ Microbiol 68(12): 6425-6428.

[14]. Gu X-C, et al. (2014) Cloning and analysis of bile salt hydrolase genes from Lactobacillus plantarum CGMCC No. 8198. Biotech Lett 36(5): 975-983.

[15]. Zhang WY, et al. (2009) Molecular cloning and characterization of bile salt hydrolase in Lactobacillus casei Zhang. Ann Microbiol 59(4): 721-726.

[16]. Kim GB,Lee B (2008) Genetic analysis of a bile salt hydrolase in Bifidobacterium animalis subsp. lactis KL612.J Appl Microbiol 105(3): 778-790.

[17]. Kumar RS, et al. (2006) Structural and functional analysis of a conjugated bile salt hydrolase from Bifidobacterium longum reveals an evolutionary relationship with penicillin V acylase.J Biol Chem 281(43): 32516-32525.

[18]. Tanaka H, Hashiba H, Kok J,Mierau I (2000) Bile salt hydrolase of Bifidobacterium longum : biochemical and genetic characterization. Appl Environ Microbiol 66(6): 2502-2512.

[19]. Begley M, Hill C, Gahan CG (2006) Bile salt hydrolase activity in probiotics. Appl Environ Microbiol 72(3): 1729-1738.

[20]. Malpeli A, et al. (2015) Effect of daily consumption of Lactobacillus reuteri CRL 1098 on cholesterol reduction in hypercholesterolemic subjects.Food Nutr Sci 6(17): 1583-1590 
[21]. Ryan PM, et al. (2015) Functional food addressing heart health: do we have to target the gut microbiota. Curr Opin Clin Nutr Metab Care 18(6): 566571

[22]. Organization WH (2002) Guidelines for the Evaluation of Probiotics in Food. Report of a Joint FAO/WHO Working Group on Drafting Guidelines for the Evaluation of Probiotics in Food. FAO, WHO, London, Ont., Canada, London, ON, Canada.

[23]. Taranto MP, et al. (2000) Effect of Lactobacillus reuteri on the prevention of hypercholesterolemia in mice. J Dairy Sci 83(3): 401-403.

[24]. Taranto MP, Sesma F, Pesce de Ruiz Holgado A, de Valdez GF (1997) Bile salts hydrolase plays a key role on cholesterol removal by Lactobacillus reuteri. Biotech Lett 19(9): 845-847.

[25]. Mechoud MA, et al. (2012) Lactobacillus reuteri CRL1098 soluble factors modulate tumor necrosis factor alpha production in peripheral blood mononuclear cells: Involvement of lipid rafts. Int Immunopharmacol 14(4): 446453.

[26]. Molina V, Médici M, de Valdez GF, Taranto MP (2012) Soybean-based functional food with vitamin B 12-producing lactic acid bacteria. J Funct Foods 4(4): 831-836.

[27]. Taranto MP, et al. (2003) Lactobacillus reuteri CRL1098 produces cobalamin. J Bacteriol 185(18): 5643-5647.

[28]. Zhang Y, Zhang H (2013), The effect of probiotics on lipid metabolism. 2013: INTECH Open Access Publisher.

[29]. De Man JC, Rogosa M,Sharpe ME (1960) A medium for the cultivation of lactobacilli. J Appl Microbiol 23(1): 130-135.

[30]. Pospiech A, Neumann B (1995) A versatile quick-prep of genomic DNA from gram-positive bacteria. Trends Genet 11(6): 217-218.

[31]. Birnboim HC, Doly J (1979) A rapid alkaline extraction procedure for screening recombinant plasmid DNA. Nucleic Acids Res 7(6): 1513-1523

[32]. Kumar R, et al. (2013) Molecular cloning, characterization and heterologous expression of bile salt hydrolase (Bsh) from Lactobacillus fermentum NCDO394. Mol Biol Rep 40(8): 5057-5066.

[33]. Sambrook J, Fritsch EF, Maniatis T (1989) Molecular cloning: A laboratory manual Cold spring Harbor Laboratory press. New York: 931-957.

[34]. Church FC (1985) An o-phthalaldehyde spectrophotometric assay for proteolytic enzymes. Prog Clin Biol Res 180: 303-305.

[35]. Raya R, et al. (1998) Multiple transcriptional control of the Lactococcus lactis trp operon. J Bacteriol 180(12): 3174-3180

[36]. Schmittgen TD,Livak KJ (2008) Analyzing real-time PCR data by the comparative CT method. Nature protocols 3(6): 1101-1108.

[37]. Elkins CA, Moser SA,Savage DC (2001) Genes encoding bile salt hydrolases and conjugated bile salt transporters in Lactobacillus johnsonii 100-100 and other Lactobacillus species. Microbiology 147(12): 3403-3412

[38]. Taranto MP, Sesma F, Font de Valdez G (1999) Localization and primary characterization of bile salt hydrolase from Lactobacillus reuteri. Biotech Lett 21(11): 935-938.

[39]. Bustos AY, et al. (2012) Relationship between bile salt hydrolase activity, changes in the internal $\mathrm{pH}$ and tolerance to bile acids in lactic acid bacteria. Biotech Lett 34(8): 1511-1518.

[40]. Bi J, Liu S, Du G, Chen J (2016) Bile salt tolerance of Lactococcus lactis is enhanced by expression of bile salt hydrolase thereby producing less bile acid in the cells. Biotech Lett: 38(4): 659-665

[41]. Bustos AY, et al. (2015) Proteomic analysis of the probiotic Lactobacillus reuteri CRL1098 reveals novel tolerance biomarkers to bile acid-induced stress. Food Res Int77: 599-607.

[42]. Koskenniemi K, et al. (2011) Proteomics and transcriptomics characterization of bile stress response in probiotic Lactobacillus rhamnosus GG. Mol Cell Proteomics 10(2): M110. 002741.

[43]. Duary RK, Batish VK, Grover S (2012) Relative gene expression of bile salt hydrolase and surface proteins in two putative indigenous Lactobacillus plantarum strains under in vitro gut conditions. Mol Biol Rep 39(3): 2541-2552.

[44]. Bron PA, et al. (2004) Identification of Lactobacillus plantarum genes that are induced in the gastrointestinal tract of mice. J Bacteriol 186(17): 57215729. 